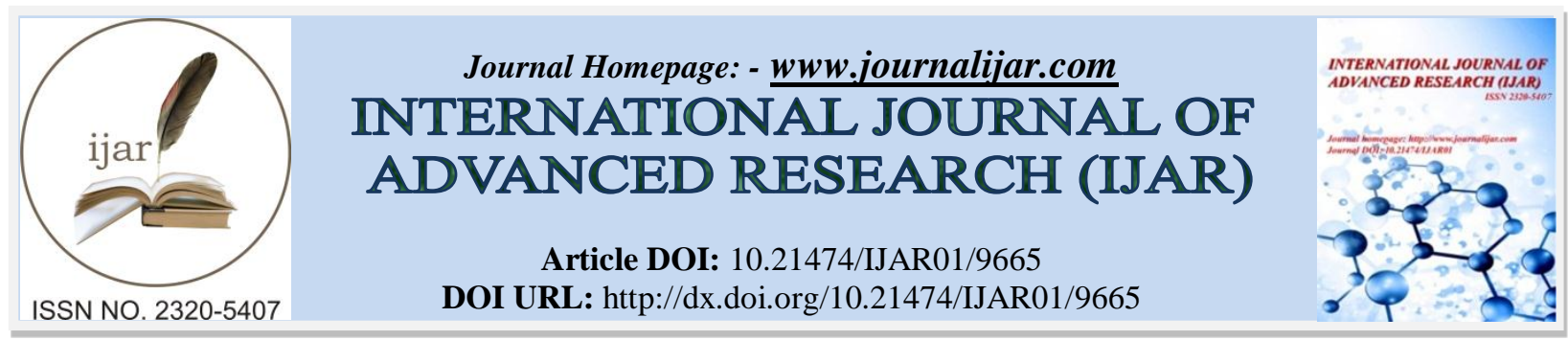

RESEARCH ARTICLE

\title{
ERGONOMICS FACTORS, MENTAL AND PHYSICAL LOADS AMONG HEALTH-CARE WORKERS.
}

\author{
Abdulrahman M Basahel ${ }^{1}$ and Feras Khaled Tajuddin ${ }^{2}$. \\ Department of Industrial Engineering, Faculty of Engineering, King Abdulaziz University, Jeddah - Saudi Arabia.
}

\section{Manuscript Info}

Manuscript History

Received: 04 July 2019

Final Accepted: 06 August 2019

Published: September 2019

Key words:-

Ergonomics Factors, Mental Load,

Physical Load, Health-Care Workers.

\begin{abstract}
Organizational ergonomics aspects, physical and mental task demands are considerable safety factors that can lead to poor performance and injuries in particular, health-care sector. This study aimed at identifying the main ergonomics factors that impact patient safety level and healthcare care workers performance. The descriptive analysis was used in this study using a questionnaire distributed to a 284 healthcare workers in a large hospital in Saudi Arabia including doctors after getting the consent form. The sample included three types of jobs; doctors, nurses and technicians to find the factors influencing patient safety and healthcare workers performance through NASA-TLX analysis results. The AHP technique was applied to determine the priority of five main ergonomic factors based on a second questionnaire to investigate the importance weights for each factor. The results of this study revealed that the organizational managerial factor was the most significant factor. Moreover, leadership was the most significant subfactor from the operational managerial level. Team work was the most significant sub-factor from the workgroup/team level. Behavior was the most significant sub-factor from the individual worker level, mental load was the most significant sub-factor from the task work load level and finally radiation was the most significant sub-factor from the work environment level.
\end{abstract}

Copy Right, IJAR, 2019,. All rights reserved.

\section{Introduction:-}

Ergonomics factors have been at the center of discussion about patient safety; they have concepts, theories and methods that can be used and applied to enhance safety and reduce preventable patient harm. However, the studies that discussed the actual ergonomics factors such as organizational, workgroup, individual worker, task work load and work environment that influence the relation between healthcare workers performance and patient safety are still poor ${ }^{[1]}$. Current development in HFE (Human Factors and Ergonomics) application and research in health care enlarge the HFE role to develop the healthcare organization services and delivery. Improvements in the healthcare delivery way lead to improvement in the healthcare quality. For example, medical devices ergonomic design can support safe medications administration for nurses ${ }^{[2]}$. HFE creates significant contributions to this system by helping in healthcare technologies, processes and systems design ${ }^{[3]}$. Therefore, this study is trying to find the actual effect on HFE as a comprehensive concept and factors that affect all the aspects of the healthcare system and healthcare workers performance, which in turn could influence the patient safety level.

Corresponding Author:-Abdulrahman M Basahel.

Address:-Department of Industrial Engineering, Faculty of Engineering, King Abdulaziz University, Jeddah - Saudi Arabia. 
In fact, within the lack of such studies concentrating on the effect of human factors and ergonomics and safety on both patient safety and healthcare workers performance in the Middle East and in particular Saudi Arabia. Therefore, this study will contribute on highlighting this relation on the different cultures and encourage further studies to hold comparisons and build on its results.

Human factors directly affect the health care provided to the patients. Human error can lead to harm to the patients. Therefore, there is a need for advanced work mechanisms and advanced technology to reduce the error rate. The resilience of the system and the ease of movement between routine processes or change can help on improving the performance of health care providers and thus benefit the safety of patients. The performance of hospital staff directly affects health care, so performance should be evaluated periodically ${ }^{[1]}$.

From the factors that affect the safety of health care providers or the impact of their work and therefore affect the safety of patients are electrical injury, radiation, noise, light level and temperature. Lighting is of good quality, suitable temperature, and exposure to obstacles in the hospital ladders does not exist ${ }^{[4]}$.

Also mental demand, time demand and its impact on the performance of nurses has been studied where an appropriate number of nurses should be provided within the hospital to reduce the workload, and the resources are available to facilitate the work of nurses ${ }^{[5]}$.

\section{Methodology:-}

In the current research, the aim was to identify the influence of ergonomics factors on worker performance and patient safety in healthcare organization including doctors, nurses and technicians. Thus, the research study was adopted the descriptive correlational research design where a questionnaire was developed and distributed to collect the required data. The questionnaire was developed based on the studies of ${ }^{[6]}$. In the current research, different methods were used that were developed by questionnaire and Analytic Hierarchy Process (AHP). The questionnaire was used to find the most prevailing demands affecting the workers. The AHP was used to find the highest percentage in the main factors affecting the main aim and the highest percentage of sub factors affecting each main factor. The Five factors that were investigated are organizational management, workgroup team, individual worker and task workloads.

The method for data collection that was used in this study is the questionnaire. Sample members were selected (based on the inclusion criteria) to fill the questionnaire. In order to collect the primary data of this study, the researcher developed a questionnaire consisted of two sections; general information and NASA-TLX analysis. In order to validate the study tool, it was presented in its initial form to a panel of experts in the field of healthcare and patient safety to make their comments where all their comments were taken into consideration. The construction validity was verified by distributing it to a pilot sample from outside the study sample. The construction validity was calculated by using the Pearson correlation coefficient to find the correlation coefficients in its field, and the Coefficient of correlation of the paragraph by the total mark of the tool, besides the correlation coefficient values of the total fields and the total mark of the study tool. After finding the ergonomics factors that impact health care worker and patient safety using the questionnaire tool, AHP was used to find the priority of these factors.

The data were organized through the descriptive statistics that characterize or describe data through shortening them into further clear terms with no miss or distort a lot of the data. It includes percentages, summary tables and charts to define the characteristics of the sample. Kruskal-Wallis $\mathrm{H}$ test was also applied, it is a non-parametric method. It is use for comparing two or more independent samples of equal or different sample sizes. The parametric equivalent of the Kruskal-Wallis test is the one-way analysis of variance (ANOVA). Then the null hypothesis is that the medians of all groups are equal, and the alternative hypothesis is that at least one population median of one group is different from the population median of at least one other group ${ }^{[7]}$.

\section{Results:-}

The main factors in this study include; Organizational managerial (O), Workgroup/Team (W), Individual worker (I), Task work load (T) and Work Environment (WE). In order to find the most affecting factor among them, the following steps were followed.

\section{Building the pair-wise matrix for the main factors.}

The pair-wise matrix was built based on the means of the (15) participants who answered the questionnaire from (5 doctors, 5 nurses ad 5 technicians) where the values of the answers were between (1/9 to 9) as mentioned previously. 
When the value is equal to (1) that means that they have the same effect on each other and this case can be found when determining the effect of one factor on the same factor. While on the other values; for example, if we have (5) as a value of the effect of factor $(\mathrm{X})$ on factor $(\mathrm{Y})$, then the effect of factor $(\mathrm{Y})$ on $(\mathrm{X})$ will be $(1 / 5)$.

The summation of each column was calculated.

Building the normalized pair-wise matrix. This step is done by dividing the value in each cell with the sum of the column it is existed in as shown in table (1) below.

Table 1:-The normalized main factors pair-wise matrix

\begin{tabular}{|c|c|c|c|c|c|}
\hline & O & W & I & T & WE \\
\hline $\mathbf{O}$ & 0.2857143 & 0.4 & 0.4210526 & 0.2666667 & 0.1 \\
\hline $\mathbf{W}$ & 0.1428571 & 0.2 & 0.2105263 & 0.2666667 & 0.2 \\
\hline $\mathbf{I}$ & 0.1428571 & 0.2 & 0.2105263 & 0.2666667 & 0.4 \\
\hline $\mathbf{T}$ & 0.1428571 & 0.1 & 0.1052632 & 0.1333333 & 0.2 \\
\hline WE & 0.2857143 & 0.1 & 0.0526316 & 0.0666667 & 0.1 \\
\hline
\end{tabular}

Calculating the factors weight.

The factor weight was calculated by dividing the sum of each row in the normalized matrix by the number of factors (2) as shown in table (8) below.

Table 2:-Factor weights for the normalized main factors pair-wise matrix

\begin{tabular}{|c|c|c|c|c|c|c|}
\hline & $\mathbf{O}$ & $\mathbf{W}$ & $\mathbf{I}$ & $\mathbf{T}$ & WE & Factor weight \\
\hline $\mathbf{O}$ & 0.28 & 0.4 & 0.42 & 0.26 & 0.1 & 0.294 \\
\hline $\mathbf{W}$ & 0.14 & 0.2 & 0.21 & 0.26 & 0.2 & 0.204 \\
\hline $\mathbf{I}$ & 0.14 & 0.2 & 0.21 & 0.26 & 0.4 & 0.244 \\
\hline $\mathbf{T}$ & 0.14 & 0.1 & 0.10 & 0.13 & 0.2 & 0.136 \\
\hline $\mathbf{W E}$ & 0.28 & 0.1 & 0.05 & 0.06 & 0.1 & 0.121 \\
\hline
\end{tabular}

As shown in table (8) above, it can be noticed that organizational managerial was the most significant factor with a factor weight of (0.294) followed by individual worker with (0.244), workgroup team, task work load and finally the work environment factor.

\section{Calculating the consistency of the matrix.}

$\lambda_{\max }$ was calculated by multiplying the factor weight for each factor with the summation of the pairwise matrix in the first step as follows:

$\lambda_{\max }=3.5(0.294687)+5(0.20401)+4.75(0.24401)+7.5(0.136291)+10(0.121003)=5.442706767$

Then, the consistency index (C.I.) can be calculated by the following equation.

$$
\text { C. } I .=\frac{\lambda_{\max }-n}{n-1}=\frac{5.442706767-5}{4}=0.110676692
$$

Finally, the consistency ratio (CR) was calculated as follows:

$$
C R=\frac{C . I .}{R . I}=\frac{0.110676692}{1.12}=0.098818475
$$

As illustrated in the methodology section, the sub-factors in this study include; Organizational managerial (leadership and communication), Workgroup/Team (teamwork, structure, process and supervisors), Individual worker (behavior, situation, awareness, skill and Experience), Task work load (physical and mental) and Work Environment (Equipment, Noise, Radiation and Lighting). In order to find the most affecting factor among them, the following steps were followed for each sub-factor. The following table shows a summary for the significant subfactors for each main factor where the consistency was checked as in the main factors case.

Table 3:-Factor weights for the sub-factors

\begin{tabular}{|c|c|}
\hline Sub-factor & Factor weight \\
\hline Manager's leadership and communication & 0.89 \\
\hline Leader ship & 0.111 \\
\hline Communication & \\
\hline
\end{tabular}




\begin{tabular}{|c|c|}
\hline Work group/team & 0.5748215 \\
\hline Team work & 0.2910925 \\
\hline Structure & 0.0899275 \\
\hline Process & 0.0441585 \\
\hline Supervisors & 0.472465 \\
\hline Individual worker & 0.2072771 \\
\hline Behavior & 0.1294799 \\
\hline Situation awareness & 0.190778 \\
\hline Skill & 0.125 \\
\hline Experience & 0.875 \\
\hline Task work load & \\
\hline Physical & 0.0598834 \\
\hline Mental & 0.267156 \\
\hline Work environment & 0.4466431 \\
\hline Equipment & 0.2263175 \\
\hline Noise & \\
\hline Radiation &
\end{tabular}

As shown in table (3) above, it can be noticed that leadership was the most significant sub-factor from the operational managerial level with a factor weight of (0.89) followed by communication with (0.111). Team work was the most significant sub-factor from the workgroup/team level with a factor weight of (0.57) followed by structure with (0.29), process and finally supervisors. Behavior was the most significant sub-factor from the individual worker level with a factor weight of (0.47) followed by situation awareness with (0.21), experience and finally skill. Mental load was the most significant sub-factor from the task work load level with a factor weight of (0.88) followed by the physical load with (0.125). Finally, radiation was the most significant sub-factor from the work environment level with a factor weight of (0.45) followed by noise with $(0.27)$, lighting and finally equipment. The following results represent the participants' answers to the questions related to the third ergonomics factor (Task Work Load).

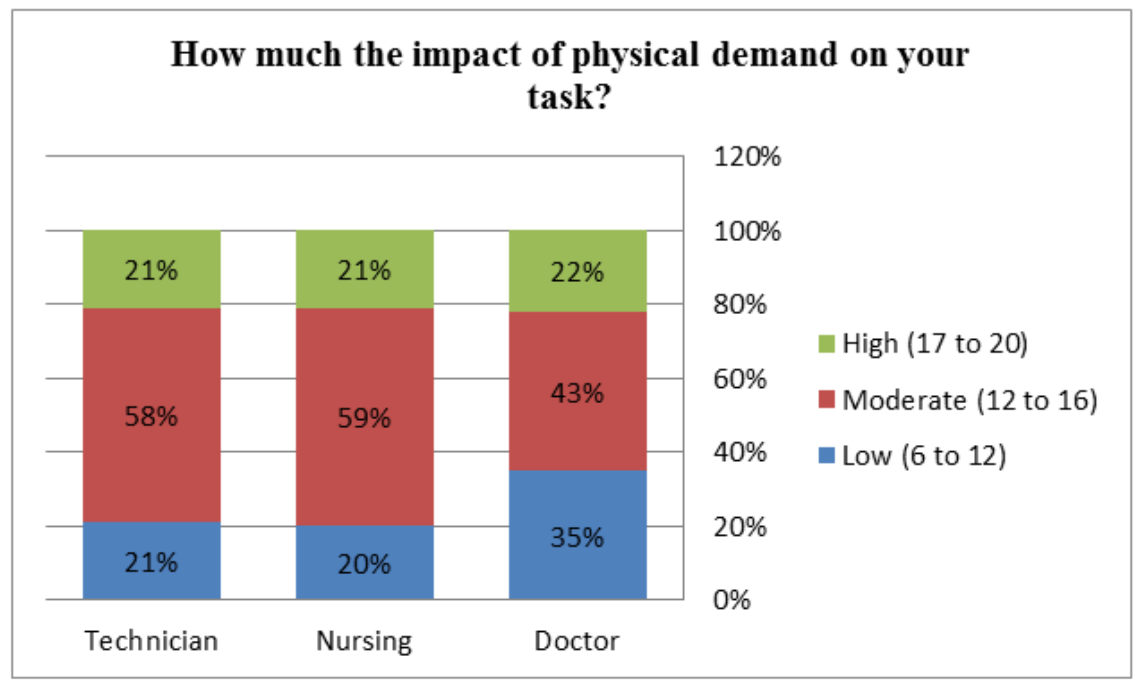

Figure 1:-The respondents' answers to the question "How much the impact of physical demand on your task?"

(Borg-CR10)

Figure (1) shows the participants' evaluation of the impact of physical demand on their task. The overall evaluation was moderate (12 to 16 ) by $51 \%$. The results confirmed that both the nurses and technician's tasks were more influenced by the physical demand by $59 \%$ and $58 \%$ respectively. This result can be attributed to the supportive 
tasks that both jobs have of dealing with patients and equipment. According to Applebaum et al., (2010), physical demand could negatively or positively affect the stress of nurses, which can impact negatively their job performance ${ }^{[8]}$. For what regards the patient safety, Karsh et al., (2006) stated that physical, cognitive and social/behavioral demands can impact patient safety ${ }^{[9]}$. Patient safety also is linked with the workers performance as confirmed by ${ }^{[10]}$. In order to find whether there are significant differences between the type of job variable and the Physical Demand (Borg-CR10), Kruskal-Wallis H test was conducted It can be noted that there are no statistical significant differences between the doctor, nursing and technician for the physical demand (Borg-CR10), the value of ChiSquare $(\chi 2)(2.247)$ as the $p$ value is $(0.325)$, which is more than the significant level $(0.05)$.

\section{NASA-TLX analysis}

The following table represents the participants' answers to the NASA-TLX analysis.

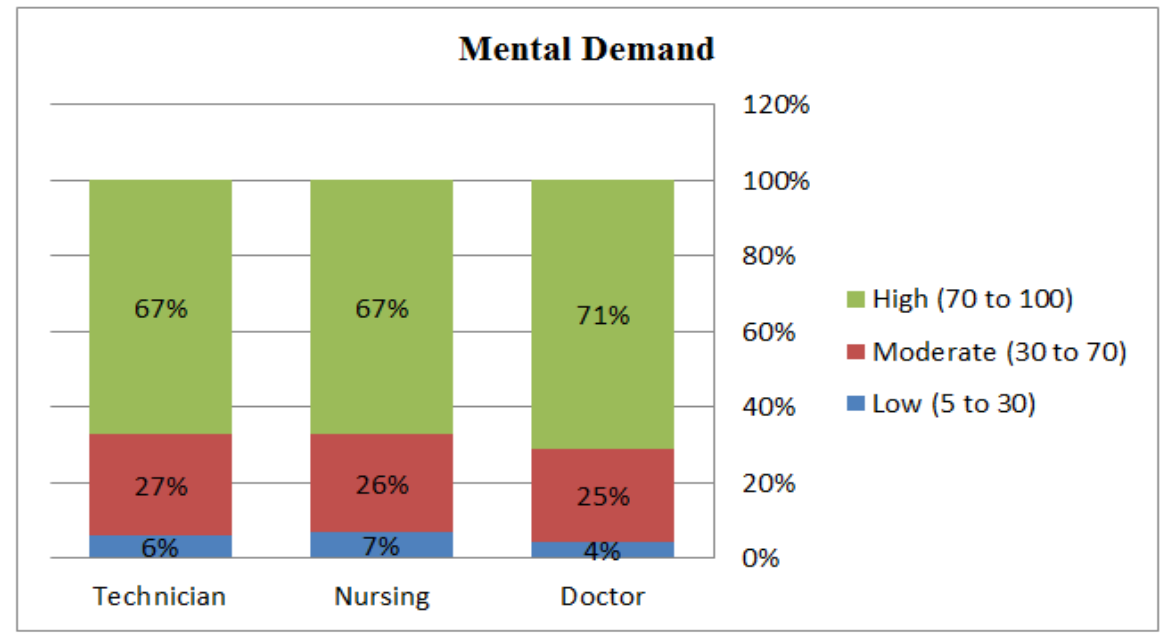

Figure 2:-The respondents' answers to the question "Mental Demand"

Figure (2) shows that most of the respondents (69\%) think that they have a high mental demand. Doctors had the highest percentage $(71 \%)$ followed by technicians and nurses with $(67 \%)$ for both of them. This result could be attributed to the responsibility doctors have on patients' lives. Bernburg et al., (2016) confirmed that doctors with high mental load show low work ability ${ }^{[11] .}$

In order to find whether there are significant differences between the type of job variable and the mental demand, Kruskal-Wallis $\mathrm{H}$ test was conducted. It can be noted that there are no statistical significant differences between the doctor, nursing and technician for the mental demand. The value of Chi-Square $(\chi 2)(0.433)$ as the p value is (0.805), which is more than the significant level (0.05) (Table (4)).

Table 4:-Kruskal- Wallis test for Mental Demand

\begin{tabular}{|c|c|c|c|c|}
\hline Type of Job & $\mathbf{N}$ & Mean & Chi-Square $\left(\boldsymbol{\chi}^{\mathbf{2}}\right)$ & 0.433 \\
\hline Nursing & 61 & 74 & & 0.805 \\
\hline Doctor & 106 & 77 & & \\
\hline Technician & 33 & 68 & & \\
\hline
\end{tabular}




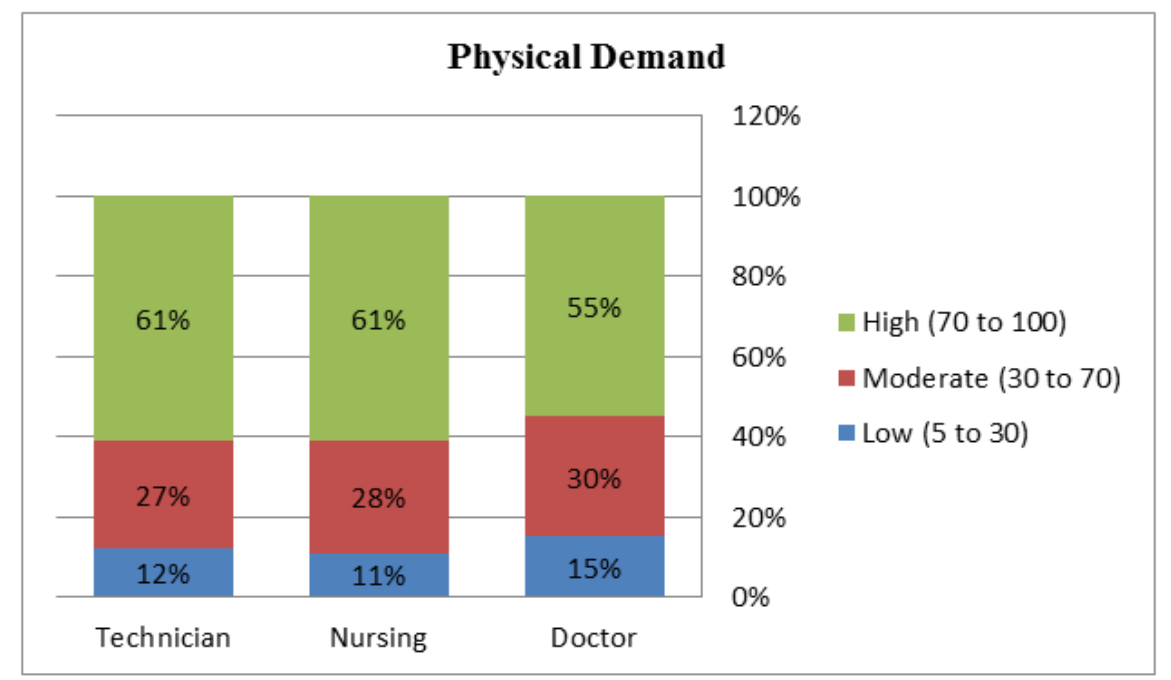

Figure 3:-The respondents' answers to the question "Physical Demand"

Figure (3) shows that most of the respondents (58\%) think that they have a high physical demand. Nurses and technicians had the highest percentage (61\%) for both followed by doctors $(55 \%)$. Nurses had the highest percentage since their work depends on the physical contact with patients; moreover, they stand a lot, run and walk to move between patients a lot besides their bending and twisting to reach the patients. Al-Homayan et al. (2013) found that the high physical demand has a negative impact on the nurses' performance ${ }^{[12]}$.

In order to find whether there are significant differences between the type of job variable and the Physical Demand, Kruskal-Wallis $\mathrm{H}$ test was conducted. It can be noted that there are no statistical significant differences between the doctor, nursing and technician for the physical demand. The value of Chi-Square $(\chi 2)(0.819)$ as the $p$ value is (0.664), which is more than the significant level (0.05) [Table 4].

Table 5:-Kruskal- Wallis test for Physical Demand

\begin{tabular}{|c|c|c|c|c|}
\hline Type of Job & $\mathbf{N}$ & Mean & Chi-Square $\left(\chi^{2}\right)$ & p-value \\
\hline Nursing & 61 & 70 & 0.819 & 0.664 \\
\hline Doctor & 106 & 65 & & \\
\hline Technician & 33 & 66 & & \\
\hline
\end{tabular}

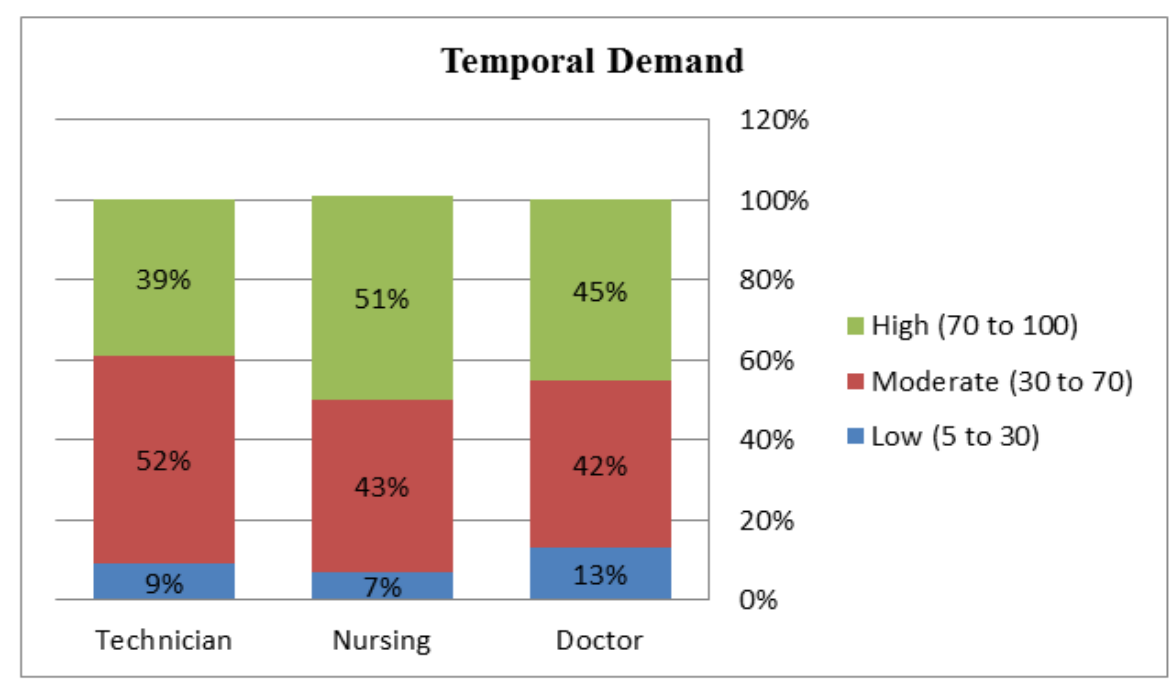

Figure 4:-The respondents' answers to the question "Temporal Demand" 
Figure (4) shows that (46\%) of the respondents think that they have a high temporal demand. Nurses had the highest percentage $(51 \%)$ followed by doctors $(45 \%)$ while technicians came last with $(39 \%)$. However, Shaikh et al., (2012) associated increased temporal demand with poor performance ${ }^{[13]}$.

In order to find whether there are significant differences between the type of job variable and the Temporal Demand, Kruskal-Wallis $\mathrm{H}$ test was conducted. It can be noted that there are no statistical significant differences between the doctor, nursing and technician for the temporal demand. The value of Chi-Square $\left(\chi^{2}\right)(1.413)$ as the $p$ value is (0.793), which is more than the significant level (0.05).

Table 6:-Kruskal- Wallis test for Temporal Demand

\begin{tabular}{|c|c|c|c|c|}
\hline Type of Job & $\mathbf{N}$ & Mean & Chi-Square $\left(\chi^{2}\right)$ & p-value \\
\hline Nursing & 61 & 68 & & 0.493 \\
Doctor & 106 & 62 & & \\
\hline Technician & 33 & 60 & & \\
\hline
\end{tabular}

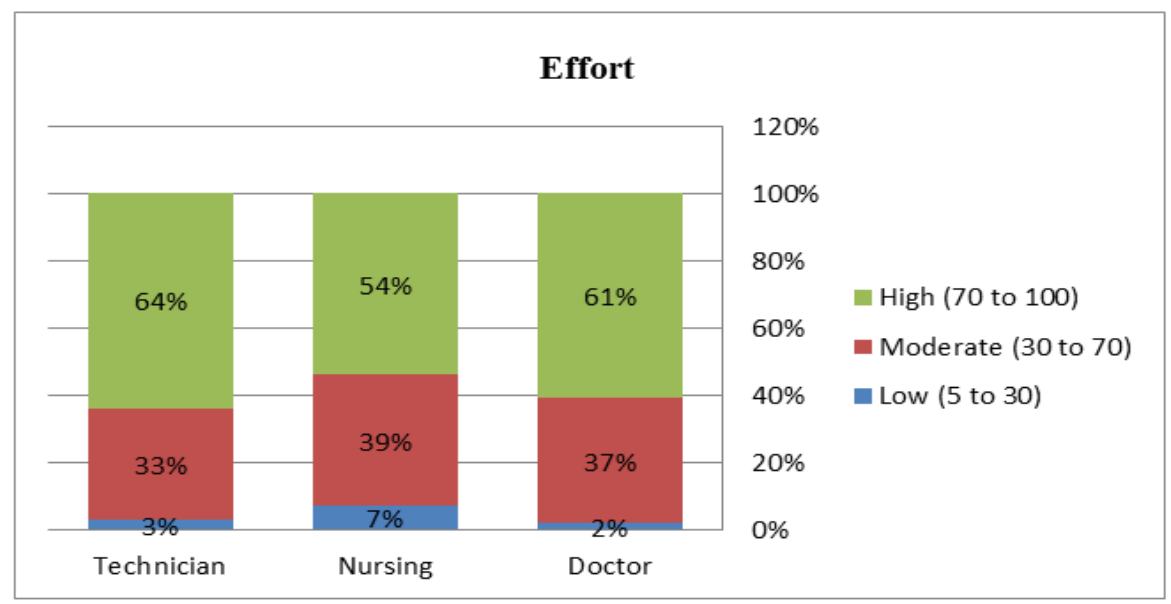

Figure 5:-The respondents' answers to the question "Effort"

Figure (5) shows that most of the respondents (60\%) thinks that they have a high effort. Technicians had the highest percentage $(64 \%)$ followed by doctors $(61 \%)$ while nurses came last with $(54 \%)$. This result is attributed to the continuous non-stop nature of some of the technicians in hospitals. High efforts may lead to fatigue and stress besides the job dissatisfaction. In order to find whether there are significant differences between the type of job variable and the effort, Kruskal-Wallis H test was conducted. It can be noted that there are no statistical significant differences between the doctor, nursing and technician for the effort. The value of Chi-Square $(\chi 2)(1.508)$ as the $p$ value is $(0.471)$, which is more than the significant level $(0.05)$.

Table 7:-Kruskal- Wallis test for Effort

\begin{tabular}{|c|c|c|c|c|}
\hline Type of Job & $\mathbf{N}$ & Mean & Chi-Square $\left(\chi^{2}\right)$ & p-value \\
\hline Nursing & 61 & 71 & & 0.471 \\
Doctor & 106 & 72 & & \\
\hline Technician & 33 & 71 & & \\
\hline
\end{tabular}




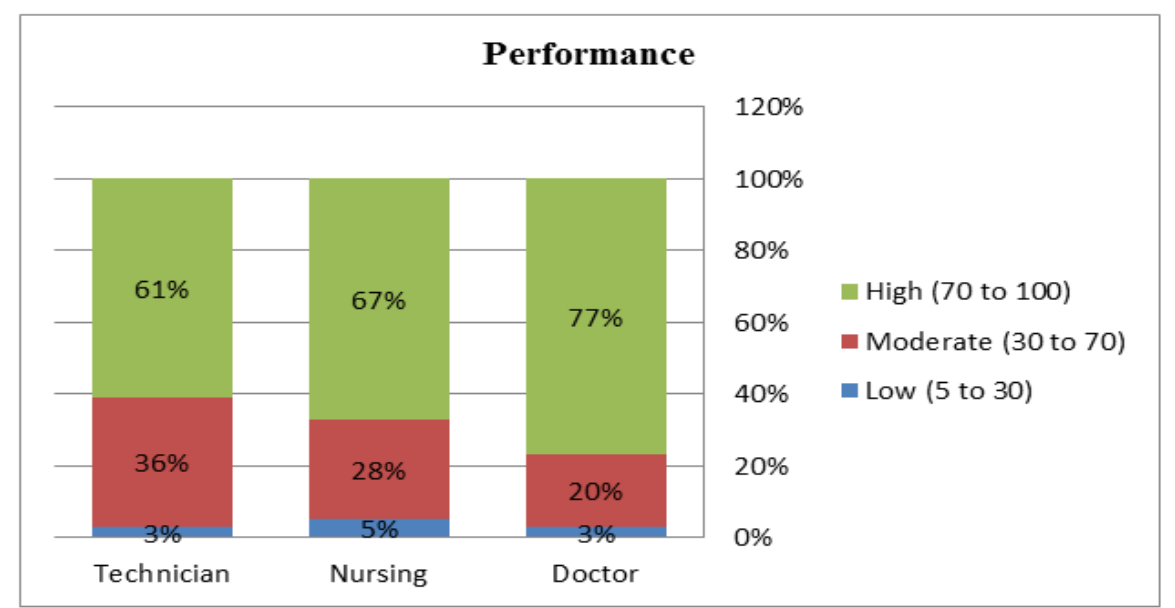

Figure 6:-The respondents' answers to the question "Performance"

Figure (6) shows that most of the respondents (72\%) think that they have a high performance. Doctors had the highest percentage $(77 \%)$ followed by nurses $(67 \%)$ while technicians came last with $(61 \%)$. This result can be attributed to the fact that doctors can see their achievement more clearly compared with other jobs that depends basically on assisting the doctor ${ }^{[14]}$.

In order to find whether there are significant differences between the type of job variable and the performance, Kruskal-Wallis $\mathrm{H}$ test was conducted. It can be noted that there are no statistical significant differences between the doctor, nursing and technician for the performance. The value of Chi-Square $(\chi 2)(4.068)$ as the $p$ value is $(0.131)$, which is more than the significant level (0.05).

Table 8:-Kruskal- Wallis test for Performance

\begin{tabular}{|c|c|c|c|c|}
\hline Type of Job & $\mathbf{N}$ & Mean & Chi-Square $\left(\chi^{2}\right)$ & p-value \\
\hline Nursing & 61 & 76 & & 0.131 \\
Doctor & 106 & 79 & & \\
\hline Technician & 33 & 75 & & \\
\hline
\end{tabular}

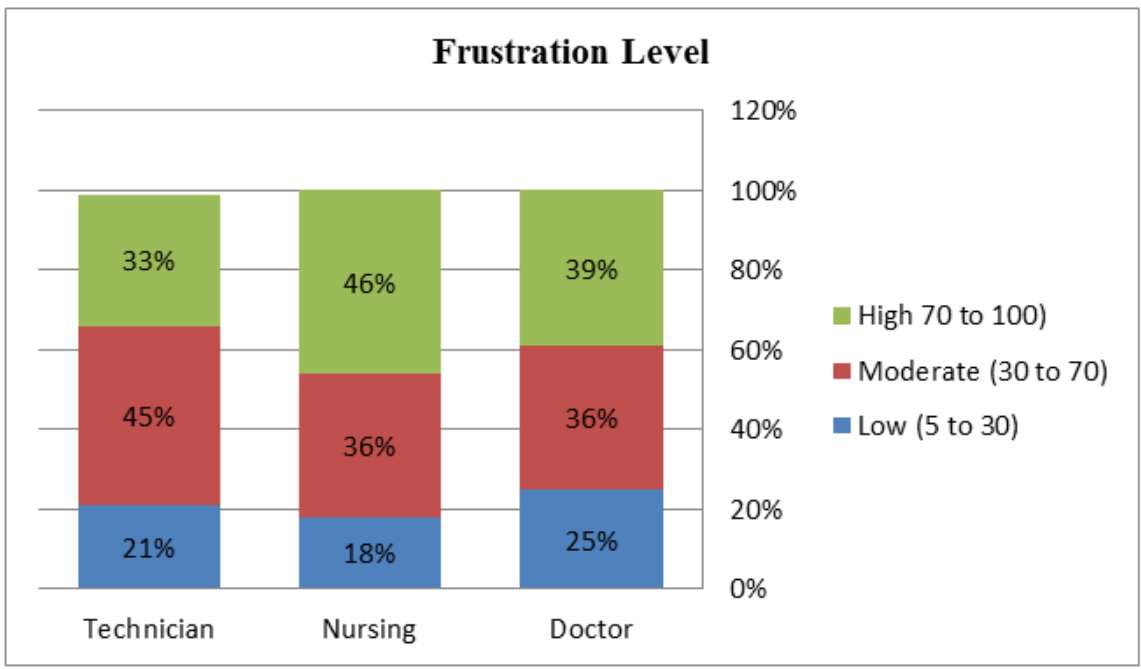

Figure 7:-The respondents' answers to the question "Frustration Level"

Figure (7) shows that (40\%) of the respondents think that they have a high frustration level. Nurses had the highest percentage $(46 \%)$ followed by doctors $(39 \%)$ while technicians came last with $(33 \%)$. Jehangir (2011) found that frustration level, being essential consequence of work related stress, affect the job satisfaction and job performance 
[15]. In order to find whether there are significant differences between the type of job variable and the Frustration Level, Kruskal-Wallis H test was conducted. It can be noted that there are no statistical significant differences between the doctor, nursing and technician for the frustration. The value of Chi-Square $\left(\chi^{2}\right)(1.603)$ as the $p$ value is (0.449), which is more than the significant level (0.05).

Table 9:-Kruskal- Wallis test for Frustration Level

\begin{tabular}{|c|c|c|c|c|}
\hline Type of Job & $\mathbf{N}$ & Mean & Chi-Square $\left(\boldsymbol{\chi}^{\mathbf{2}}\right)$ & p-value \\
\hline Nursing & 61 & 58 & & 0.449 \\
\hline Doctor & 106 & 54 & & \\
\hline Technician & 33 & 52 & & \\
\hline
\end{tabular}

Table (10) below shows the overall correlation between the three types of jobs for the NASA-TLX analysis. Form the table, it can be noticed that the value of Chi-Square $\left(\chi^{2}\right)(0.593)$ with p-value $(0.744)$ that is greater than the level of significance (alpha level) (0.05), which mean that there are no significant differences between the type of job regarding NASA-TLX.

Table 10:-Kruskal- Wallis test forNASA-TLX

\begin{tabular}{|c|c|c|c|c|}
\hline Type of Job & $\mathbf{N}$ & Mean & Chi-Square $\left(\boldsymbol{\chi}^{\mathbf{2}}\right)$ & p-value \\
\hline Nursing & 61 & 75 & 0.593 & 0.744 \\
\hline Doctor & 106 & 72 & & \\
\hline Technician & 33 & 70 & & \\
\hline
\end{tabular}

\section{Conclusion:-}

After calculating the weights of the ergonomic factors; it was found that the organizational managerial factor was the most significant factor where leadership was the most significant sub-factor from the operational managerial level, team work was the most significant sub-factor from the workgroup/team level, behavior was the most significant sub-factor from the individual worker level, mental load was the most significant sub-factor from the task work load level and finally radiation was the most significant sub-factor from the work environment level. As the mental demand is the leading load that faces the health workers, the heath organizations should held meeting and discuss the causes of such loads by hiring psychological experts. The organizational managerial aspect should be reinforced in the health organizations with collaboration with the related authorities. For further research, this study recommends spate each of the health workers in order to come up with more detailed results.

\section{Financial Support and Sponsorship}

Nil

\section{Conflicts of Interest}

There are no confects of interest

\section{References:-}

1. Carayon P, Xie A, Kianfar S, Human factors and ergonomics as a patient safety practice, BMJ Qual Saf 2014; 23: 196-205.

2. Carayon P, Hundt AS, Wetterneck T B, Nurses' acceptance of Smart IV pump technology, International journal of medical informatics 2010; 79: 401-411.

3. Carayon P, Emerging role of human factors and ergonomics in healthcare delivery-A new field of application and influence for the IEA, Work 2012; 41: 5037-5040.

4. Abdel-Wahed A, Ghandour A A, Elsaidy, W H, Risk assessment of physical health hazards in Al-Azhar University Hospital in new Damietta, Egypt, The Egyptian Journal of Hospital Medicine 2013; 31:1-17.

5. Umansky J, Workload in Nursing: A Descriptive Study Using Cognitive Work Analysis; 2015.

6. Drake D J, Nurse leader behavior and patient safety; 2015.

7. Conover W J, Conover W J, Practical nonparametric statistics; 1980.

8. Applebaum D, Fowler S, Fiedler N, Osinubi O, Robson M, The impact of environmental factors on nursing stress, job satisfaction, and turnover intention, The Journal of nursing administration 2010; 40: 323.

9. Karsh B, Holden R, Alper S, Or C, A human factors engineering paradigm for patient safety: designing to support the performance of the healthcare professional, BMJ Quality \& Safety 2006; 15: i59-i65. 
10. Sokas R, Braun B, Chenven L, Cloonan P, Fagan K, Hemphill R R, Hogan E, Storey E, Frontline hospital workers and the worker safety/patient safety nexus, Joint Commission journal on quality and patient safety 2013; 39: 185-192.

11. Bernburg M, Vitzthum K, Groneberg D A, Mache S, Physicians' occupational stress, depressive symptoms and work ability in relation to their working environment: a cross-sectional study of differences among medical residents with various specialties working in German hospitals, BMJ open 2016; 6: e011369.

12. Al-Homayan A M, Shamsudin F M, Subramaniam C, Islam R, Impacts of job demands on nurses'performance working in public hospitals, American Journal of Applied Sciences 2013; 10: 1050.

13. Shaikh S, Cobb S V G, Golightly D, Segal J I, Haslegrave C M, Investigating the effects of physical and cognitive demands on the quality of performance under different pacing levels, Work 2012; 41: 1625-1631.

14. Yun S H, Kim S J, Oh E G, Healthcare Professional's Knowledge, Perception and Performance on Early Enteral Nutrition for Critically Ill Patients, Korean Journal of Critical Care Medicine 2012; 27

15. Jehangir M, Causes and effects of job stress on the performance and job satisfaction of para-medics of plubic sector hospitals, (a case study of public sector hospitals of peshawar, in: Doctoral dissertation, Qurtaba University of Science \& Information Technology Peshawar, PAKISTAN; 2011. 